\section{Finely-tuned regulation of AMP-activated protein kinase is crucial for human adult erythropoiesis}

Meriem Ladli, ${ }^{1,2,3,4}$ Cyrielle Richard ${ }^{1,2,3,4}$, Lilia Cantero Aguilar, ${ }^{1,2,3,4}$ Sarah

Ducamp,,$^{1,2,3,4}$ Sabrina Bondu, ,,2,3,4 Pierre Sujobert, ${ }^{1,2,3}$ Jérôme Tamburini, ${ }^{1,2,3}$

Catherine Lacombe, ${ }^{1,2,3,4}$ Nabih Azar, ${ }^{5}$ Marc Foretz, ${ }^{1,2,3,4}$ Yael Zermati, 1,2,3,4

Patrick Mayeux, ${ }^{1,2,3,4}$ Benoit Viollet ${ }^{1,2,3,4}$ and Frédérique Verdier ${ }^{1,2,3,4}$

${ }^{1}$ Institut Cochin, INSERM U1016; ${ }^{2}$ CNRS UMR 8104, Paris; ${ }^{3}$ Université Paris Descartes, Sorbonne Paris Cité; ${ }^{4}$ Labex GREX and ${ }^{5}$ Service d'Hémobiologie, Hôpital La Pitié Salpétrière, Paris, France

\section{ABSTRACT}

A $\mathrm{MP}$-activated protein kinase (AMPK) is a heterotrimeric complex containing $\alpha, \beta$, and $\gamma$ subunits involved in maintaining integrity and survival of murine red blood cells. Indeed, Ampk $\alpha 1^{-1}$, Ampk $\beta 1^{-\%}$ and Ampk $\gamma 1^{-\%}$ mice develop hemolytic anemia and the plasma membrane of their red blood cells shows elasticity defects. The membrane composition evolves continuously along erythropoiesis and during red blood cell maturation; defects due to the absence of Ampk could be initiated during erythropoiesis. We, therefore, studied the role of AMPK during human erythropoiesis. Our data show that AMPK activation had two distinct phases in primary erythroblasts. The phosphorylation of AMPK (Thr172) and its target acetyl CoA carboxylase (Ser79) was elevated in immature erythroblasts (glycophorin $\mathrm{A}^{\text {low}}$ ), then decreased conjointly with erythroid differentiation. In erythroblasts, knockdown of the $\alpha 1$ catalytic subunit by short hairpin RNA led to a decrease in cell proliferation and alterations in the expression of membrane proteins (band 3 and glycophorin A) associated with an increase in phosphorylation of adducin (Ser726). AMPK activation in mature erythroblasts (glycophorin $\mathrm{A}^{\text {high }}$ ), achieved through the use of direct activators (GSK621 and compound 991), induced cell cycle arrest in the S phase, the induction of autophagy and caspase-dependent apoptosis, whereas no such effects were observed in similarly treated immature erythroblasts. Thus, our work suggests that AMPK activation during the final stages of erythropoiesis is deleterious. As the use of direct AMPK activators is being considered as a treatment in several pathologies (diabetes, acute myeloid leukemia), this observation is pivotal. Our data highlighted the importance of the finely-tuned regulation of AMPK during human erythropoiesis.

\section{Introduction}

Mammalian AMP-activated protein kinase (AMPK) is a highly conserved eukaryotic serine/threonine protein kinase and a heterotrimeric complex consisting of a single catalytic $(\alpha)$ and two regulatory $(\beta$ and $\gamma)$ subunits, encoded by different genes $(\alpha 1, \alpha 2, \beta 1, \beta 2, \gamma 1, \gamma 2$, and $\gamma 3)$. In the case of energy depletion, a decrease in the cellular ATP-to-AMP ratio leads to allosteric AMPK activation by AMP but also by the phosphorylation of Thr172 within the activation loop segment of the $\alpha$ subunit by an upstream AMPK kinase, liver kinase B1 (LKB1). Another "canonical" mechanism of activation involves the phosphorylation of Thr172 by calcium/calmodulin-dependent kinase kinase $\beta$ (CaMKK $\beta$ ) in response to a rise in intracellular $\mathrm{Ca}^{2+} .{ }^{1}$ Once activated, AMPK phosphorylates metabolic targets, leading to a decrease in ATP consumption and an increase in ATP production. In particular, AMPK inhibits fatty acid synthesis via phosphorylation and inactivation of acetyl-CoA-carboxylase (ACC) or induces autophagy via the phosphorylation of Unc-51 like autophagy activating kinase 1 (ULK1). ${ }^{2}$ Thus, AMPK is
Ferrata Storti Foundation

Haematologica 2019

Volume 104(5):907-918

\section{Correspondence:}

FRÉDÉRIQUE VERDIER

frederique.verdier@inserm.fr

Received: February 18, 2018.

Accepted: October 3, 2018.

Pre-published: October 11, 2018.

doi:10.3324/haematol.2018.191403

Check the online version for the most updated information on this article, online supplements, and information on authorship \& disclosures: www.haematologica.org/content/104/5/907

(C)2019 Ferrata Storti Foundation

Material published in Haematologica is covered by copyright. All rights are reserved to the Ferrata Storti Foundation. Use of published material is allowed under the following terms and conditions:

https://creativecommons.org/licenses/by-nc/4.0/legalcode. Copies of published material are allowed for personal or internal use. Sharing published material for non-commercial purposes is subject to the following conditions:

https://creativecommons. org/licenses/by-nc/4.0/legalcode, sect. 3. Reproducing and sharing published material for commercial purposes is not allowed without permission in writing from the publisher. 
a major sensor of energy status that maintains cellular energy homeostasis but also exerts non-metabolic functions such as the maintenance of cell survival, cell polarity and regulation of the cell cycle.,

Erythropoiesis is a tightly regulated process that permits the production of around two million red cells each second throughout a human life, while the total cell number has to be kept within a narrow margin. This extremely dynamic process is also very flexible, since it must increase rapidly in response to blood loss and hypoxia. Furthermore, maintaining homeostasis is crucial and an imbalance in erythropoiesis can lead to the development of erythroid pathologies such as polycythemias and anemia.

We and other groups have previously demonstrated that AMPK plays a crucial role in the integrity and survival of red blood cells. We showed that mice that are globally deficient in the catalytic subunit, Ampka1 but not in those lacking the isoform Ampka2, as well as those globally deficient in the regulatory subunits Ampk $\beta 1$ and Ampk 1 1, develop regenerative hemolytic anemia caused by increased sequestration of abnormal erythrocytes. Ampka1\%, Ampk $31^{\%}$ and Ampkr1\% mice develop splenomegaly and iron accumulation due to a compensatory response through extramedullary erythropoiesis in the spleen and enhanced erythrophagocytosis. The lifespan of erythrocytes from Ampka $1 \%$ and Ampkr $1^{\%}$ mice was shorter than that of wild-type littermates. Moreover, Ampko $1^{1-}$ and Ampk ${ }^{1 \%}$ erythrocytes were highly resistant to osmotic stress and poorly deformable in response to increasing shear stress, which is consistent with a loss of membrane elasticity. ${ }^{5-8}$

The defects in Ampk-deficient erythrocytes suggested that alterations might occur early during terminal erythroid maturation but no data were available on the importance of AMPK in human erythropoiesis. We, therefore, decided to investigate whether AMPK could be implicated in regulating the proliferation, survival and differentiation of human erythroid precursors.

In the present study, we analyzed the expression and activation of AMPK along human erythroid differentiation. Our experiments show that AMPK is highly activated in immature erythroblasts and weakly active in mature erythroblasts. We studied the impact of knocking down AMPK and of AMPK activation by direct activators. In erythroblasts, the knockdown of the AMPK $\alpha 1$ catalytic subunit expression by short hairpin (sh) RNA induced a decrease in cell proliferation and alterations in the expression or phosphorylation of membrane proteins whereas no defect in hemoglobin synthesis or erythroid maturation was observed. The activation of AMPK is necessary in immature erythroblasts but maintaining the activation in mature erythroblasts is deleterious, demonstrating that AMPK activation has to be tightly regulated during human terminal erythroid differentiation.

\section{Methods}

\section{Materials}

AMPK $\alpha 1$ and $\alpha 2$ antibodies were obtained from Graham Hardie (University of Dundee, UK); ${ }^{9,10}$ antibodies against the AMPK $\beta 1$ and $\gamma 1$ isoforms, phospho-Thr 172 AMPK, phosphoSer 79 ACC, phospho-Ser 555 ULK1, LKB1, LC3B and cleaved caspase 3 were from Cell Signaling Technology (Danvers, USA) and anti-HSC70, anti- $\alpha$ spectrin, anti-band 3 and anti-P-Ser 726 adducin antibodies were purchased from Santa Cruz Biotechnology (Santa Cruz, CA, USA). Actin (A5441) antibodies, dexamethasone and chloroquine were purchased from SigmaAldrich (Lyon, France). Anti-ankyrin antibodies were obtained from Neuromab (Davis, CA, USA) (\#75-380) and anti $\beta$-spectrin antibodies from Abcam (Cambridge, UK). Compound GSK-621 was purchased from Selleckchem (Houston, TX, USA) and 991 (5-[[6-chloro-5-(1-methylindol-5-yl)-1H-benzimidazol-2yl]oxy]-2-methyl-benzoic acid) was synthesized by Spirochem (Basel, Switzerland).

\section{Cell lines and cell culture}

$\mathrm{CD} 4^{+}$cells were obtained from human donors who gave informed consent in accordance with the Declaration of Helsinki and the study was approved by the French ministry of higher education and research review board. Granulocyte colony-stimulating factor-mobilized $\mathrm{CD} 34^{+}$cells were purified from peripheral blood after cytapheresis. CD34+ cells were isolated by positive selection using an immunomagnetic procedure (MACS CD34 isolation kit; Miltenyi Biotech (Paris, France). CD34+ cells were cultured in $5 \% \mathrm{CO}_{2}$ at $37^{\circ} \mathrm{C}$ for 7 days in IMDM medium (Life Technologies, Waltham MA, USA) containing 1\% glutamine, 15\% BIT 9500 (Stem Cell Technologies), $100 \mathrm{ng} / \mathrm{mL}$ stem cell factor, $10 \mathrm{ng} / \mathrm{mL}$ interleukin- 6 and $10 \mathrm{ng} / \mathrm{mL}$ interleukin-3 (Miltenyi Biotech). After 7 days of culture, CD36 cells corresponding to a highly purified population of human erythroid progenitors were obtained by positive selection on CD36 immunomagnetic beads (CD36 unlabeled antibodies purchased from Beckman Coulter, Villepinte, France) coupled to antimouse IgG1 microbeads purchased from Miltenyi Biotech) $\mathrm{CD} 6^{+}$cells were then cultured with $2 \mathrm{U} / \mathrm{mL}$ erythropoietin, 100 $\mathrm{ng} / \mathrm{mL}$ stem cell factor and $10 \mathrm{ng} / \mathrm{mL}$ interleukin-3 for up to 14 days for erythroid differentiation. GSK621 or compound 991 was added from day 0 after $\mathrm{CD} 36^{+}$selection; cells were counted daily and diluted to a final concentration of $0.8 \times 10^{6}$ cells $/ \mathrm{mL}$ by the addition of fresh medium containing the indicated concentration of AMPK activator. Because of interindividual variability, the kinetics of erythroid differentiation varies between different human samples. Thus, the days of culture corresponding to the same stage of differentiation have been grouped.

\section{Lentiviral constructs, Ientiviral production and cell infection}

Lentiviral constructs for control and AMPK $\alpha 1$ shRNA [(SHC002 and SHCLNG-NM006251 (TRCN00000000859), respectively)] were purchased from Sigma (Lyon, France). To obtain recombinant lentiviruses, 293T cells were transiently transfected by calcium phosphate precipitation with three different plasmids: pCMV-G (VSVG envelope coding sequence), pCMV-gag-pol and a recombinant pLKO.1 vector encoding either a control or AMPK 1 shRNA. Supernatants containing infectious lentiviral particles were concentrated by ultracentrifugation. Infections of human erythroblasts were performed at day 1 and at day 4 after CD36 cell sorting and culture in the presence of interleukin-3, stem cell factor and erythropoietin, as described above.

\section{Flow cytometry}

Cells were labeled as previously described. ${ }^{11}$ Briefly, PC7-conjugated anti-glycophorin A (GPA), APC-conjugated anti-cd49d ( $\alpha 4$ integrin) or an appropriate isotype control were purchased from Beckman Coulter; anti-BRIC6 (anti-band 3) was from the NHSBT International Blood Group Reference Laboratory (Bristol, UK). FITC-conjugated annexin V was used to measure the percentage of cell apoptosis. 


\section{Cell proliferation} dye.

Cell proliferation was determined by trypan blue exclusion

\section{Statistics}

Results are expressed as means \pm standard deviation (SD). A Student $t$ test was used to determine statistical significance. $P$ values $<0.05$ were considered statistically significant.

\section{Results}

\section{AMPK $\alpha 1$ activation is tightly regulated during human erythroid differentiation}

Because AMPK occurs as a heterotrimeric complex containing catalytic $\alpha$ subunits and regulatory $\beta$ and $\gamma$ subunits, we aimed to identify which isoforms are expressed in human erythroblasts and to study their variation during human erythroid differentiation. Human primary erythroid progenitors were maintained for up to 12 days in culture and were able to differentiate from the pro-erythroblastic stage (day 2) to the reticulocyte stage (day 12) (Figure 1A and Online Supplementary Figure S1 for cell morphology). During maturation, erythroblasts progressively acquired cell surface-specific markers such as GPA (from the pro-erythroblastic stage), band 3 (from the basophilic-erythroblastic stage) and decreased expression of $\alpha 4$ integrin at the orthochromatic erythroblast stage. They also started to synthesize hemoglobin from the basophilic stage. Western blot analysis demonstrated that the $\alpha 1$ catalytic subunit was expressed while the $\alpha 2$ isoform was not detectable and that the expression of $\alpha 1$ was constant along erythroid differentiation (Figure 1B). The regulatory subunits, $\beta 1$ and $\gamma 1$, were expressed throughout erythroid differentiation. We previously determined the copy number of individual proteins for each stage of erythroid differentiation by an absolute quantitative proteomics analysis. ${ }^{11} \mathrm{We}$ confirmed the expression of $\alpha 1, \beta 1$ and $\gamma 1$, while $\alpha 2, \beta 2$ and $\gamma 2$ isoforms were not detectable by mass spectrometry analysis (Online Supplementary Figure S2). Overall, our results suggest that $\alpha 1 / \beta 1 / \gamma 1$ is the heterotrimeric complex that is predominantly present in human erythroblasts.

Despite the global constant expression of AMPK, the activation of this protein might be modulated during differentiation. We, therefore, studied AMPK activation by detection of phosphorylation of the $\alpha 1$ catalytic subunit at Thr172 and phosphorylation of one of its substrates, ACC, at Ser79 (Figure 1C). From day 2 to day 6, the phosphorylation of AMPK and ACC was clearly detectable, but concomitantly decreased from day 8 to the end of differentiation. LKB1 was expressed throughout erythroid differentiation. These data showed the biphasic pattern of activation of AMPK during erythroid differentiation with clear activation in immature erythroblasts from the pro-erythroblast stage until day 6 when the cells were GPA ${ }^{\text {med}} /$ band $3^{\text {low }}$ (basophilic erythroblasts) and reduced activation in mature GPA $^{\text {high }} /$ band $3^{\text {med }}$ erythroblasts from day 8 to day 12 , corresponding to stages from polychromatic erythroblasts to reticulocytes.

\section{The absence of AMPK induces decreased proliferation and alterations in the expression of membrane proteins of human erythroblasts}

To decipher the role of AMPK in erythroblasts, we inhibited AMPK expression by a specific shRNA targeting the $\alpha 1$ catalytic subunit. Cells were infected by a lentivirus coding for either shAMPK $\alpha 1$ or shControl (shCtrl) at day 1 and then at day 4 after CD36 cell sorting. The decrease in $\alpha 1$ AMPK expression resulted in an expected decrease of the phosphorylation of AMPK and its substrates ACC and ULK1 (Figure 2A). No compensatory expression of the $\alpha 2$ catalytic subunit was observed in response to inhibition of the $\alpha 1$ isoform (Online Supplementary Figure S3). The inhibition of AMPK $\alpha 1$ expression did not significantly modify the differentiation of the cells. Indeed at days 6, 8 and 10 of culture, the cell population was mainly composed of basophilic erythroblasts, polychromatic erythroblasts and orthochromatic erythroblasts, respectively, and this pattern was not different when AMPK $\alpha 1$ was knocked down (Figure 2B). The morphology of the shCtrl and shAMPKa1 cells was very similar (Online Supplementary Figure S4). The percentages of hemoglobinized cells estimated at the indicated stages of differentiation were identical between the shCtrl and shAMPK $\alpha 1$ cells (Figure 2C). shAMPK $\alpha 1$ erythroblasts showed a reduced ability to proliferate compared to shCtrl erythroblasts (Figure 2D). The inhibition of $\mathrm{AMPK} \alpha 1$ expression did not significantly affect the viability of the cells measured by the trypan blue exclusion assay (Figure 2E) or by annexin V flow cytometry analysis (data not shown).

Because red cells from Ampka $1^{-1}$ and Ampkr1\% mice are highly resistant to osmotic stress and poorly deformable, the expression of membrane proteins involved in these processes was studied (Figure 3A). In shAMPK 1 polychromatic and orthochromatic erythroblasts, western blot experiments showed that the phosphorylation of adducin on Ser726 was increased while the expression of spectrins and ankyrin was not affected (Figure 3A). Western blots demonstrated that the global expression of band 3 was significantly decreased in the shAMPK $\alpha 1$ cells while its expression at the cell surface, measured by FACS, was abnormally increased (Figure 3B). FACS analyses also showed a decrease of the cell surface expression of GPA at each stage of differentiation for the shAMPK $\alpha 1$ cells in comparison to ShCtrl (39.9\% at day 6/basophilic erythroblasts, $50 \%$ at day 8/polychromatlic erythroblasts and $58.8 \%$ at day 10 /orthochromatic erythroblast versus 100\% for shCtrl) (Figure 3C). Overall, the decrease in AMPK expression induced major abnormalities in the expression of the membrane proteins band 3 and GPA and, as in murine Ampk knockout mice, led to enhanced phosphorylation of adducin. Furthermore, AMPK $\alpha 1$ knockdown provoked a decrease in cell proliferation without affecting cell viability and erythroblast maturation.

\section{Proliferation and survival of mature GPA ${ }^{\text {high }}$ erythroblasts are specifically and drastically diminished by GSK621-mediated AMPK activation}

To further investigate the role of AMPK in erythroid cells, the activation of AMPK was enhanced by GSK621, a direct, potent, novel activator of AMPK. ${ }^{12-15}$ In primary erythroblasts, the activation of AMPK by GSK621 was dose-dependent, with increased phosphorylation of T172 AMPK $\alpha$, and also gradual stimulation of the phosphorylation of the substrates of AMPK, ACC at Ser79 and ULK1 at Ser 555, from 5 to $20 \mu \mathrm{M}$ (Figure 4A). The latter dose was then used in the experiments. GSK621 was added to the medium from day 0 after CD36 cell sorting until the indicated days. GSK621 induced the phosphorylation of AMPK and its substrates at each stage of erythroid maturation (Online Supplementary 

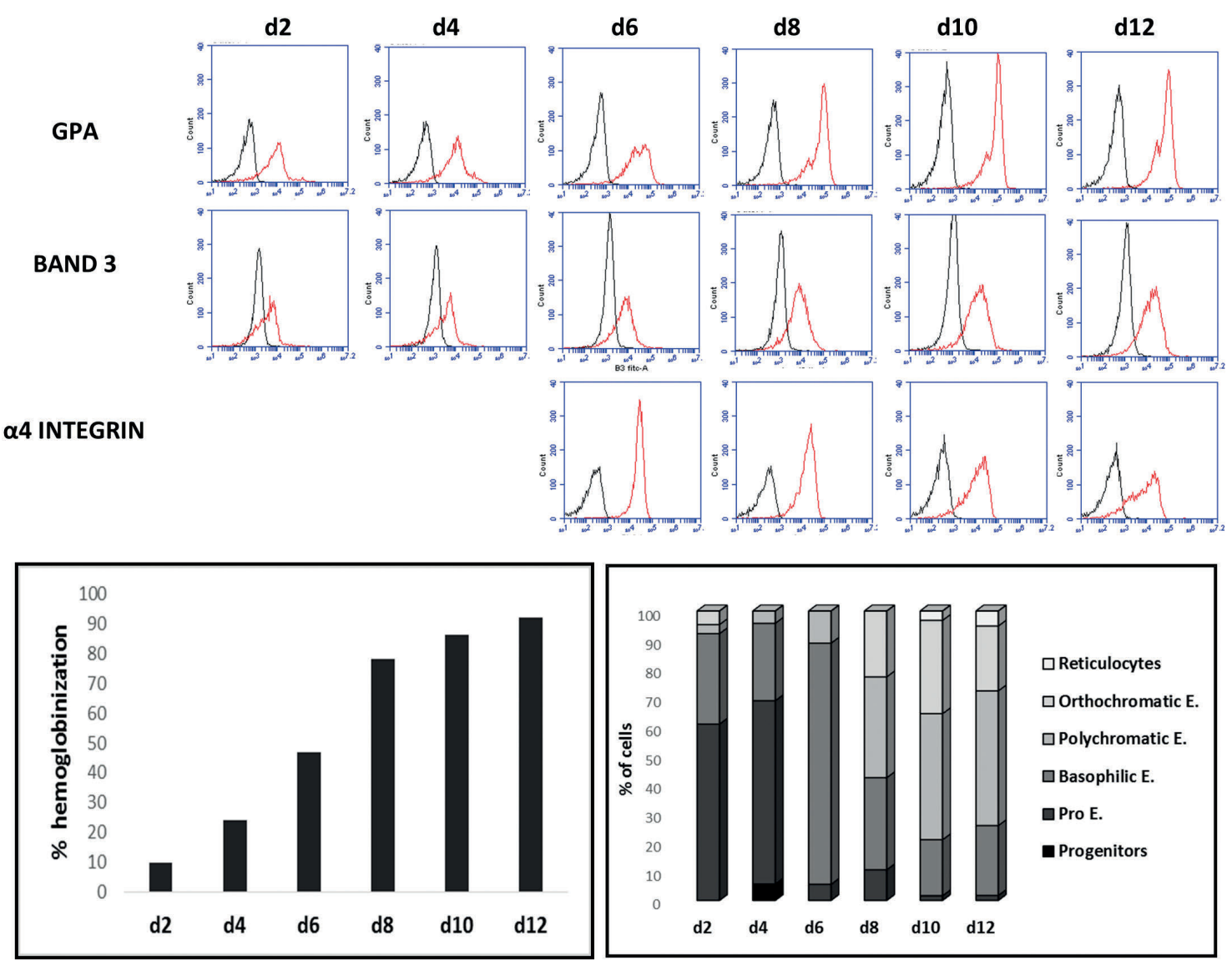

B

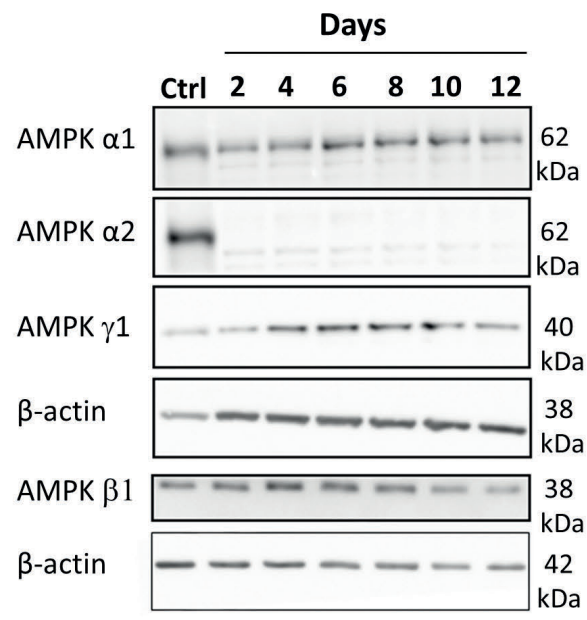

C

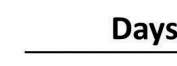

Days
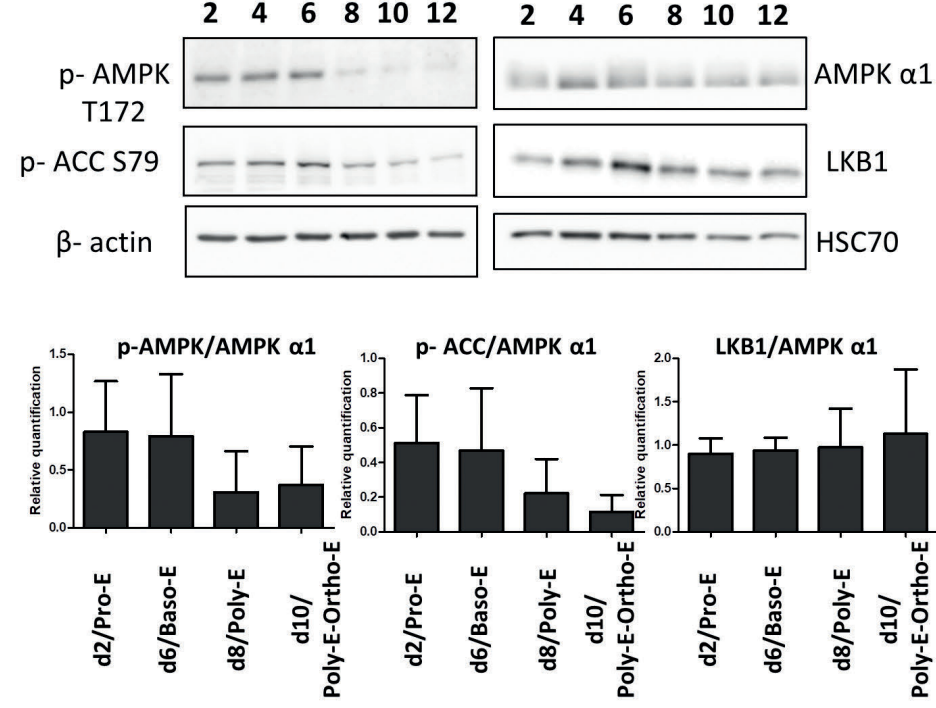

Figure 1. Expression of AMPK isoforms and AMPK activation along terminal erythroid differentiation. (A) Representative experiment of one ex vivo culture of ery throblasts derived from CD $34^{+}$cells. Cells were analyzed on days 2, 4, 6, 8, 10 and 12 after CD $36^{+}$selection. Expression of cell surface markers GPA, band 3 and $\alpha 4 \beta 1$ integrin was studied by flow cytometry along terminal erythroid differentiation. The percentage of hemoglobinized cells was determined by benzidine staining. A minimum of 200 cells were counted and the percentage of blue-stained cells among the total cell count was determined. Cell morphology was examined following staining with May-Grünwald-Giemsa; the percentage of each cell population was determined. (B) AMPK isoforms during erythropoiesis were determined by western blot. Protein extracts from human primary erythroblasts from day 2 to day 12 of culture were analyzed by western blot using anti- $\alpha 1$, $-\alpha 2$, $-\beta 1$, and $-\gamma 1$ antibodies. Anti- $\beta$-actin was used as a loading control and mouse liver protein extracts were used as a positive control for the expression of AMPK $\alpha 2$ (Ctrl). The $\alpha 1$, $\alpha 2$, and $\gamma 1$ isoforms were analyzed on the same blot, the $\beta 1$ isoform on a different one. (C) AMPK activation during erythroid differentiation. Anti-pT172 AMPK, anti-p S79 ACC, anti AMPK $\alpha 1$ and LKB1 were used. Anti- $\beta$-actin or anti-HSC70 antibodies were used as loading controls. The upper panel shows a representative experiment of three independent ones. Quantification of western blots and determination of the ratio between PAMPK/AMPK, pACC/AMPK and LKB1/AMPK $\alpha 1$ at the indicated days are presented as the mean of three independent experiments \pm SD; ns: non-significant, $* P<0.05$ (lower panel). d: day; GPA: glycophorin A; AMPK: AMP-activated protein kinase; ACC: acetyl-CoA-carboxylase; LKB1: liver kinase B1; HSC70: heat shock 70kDa protein; E: erythroblasts. 

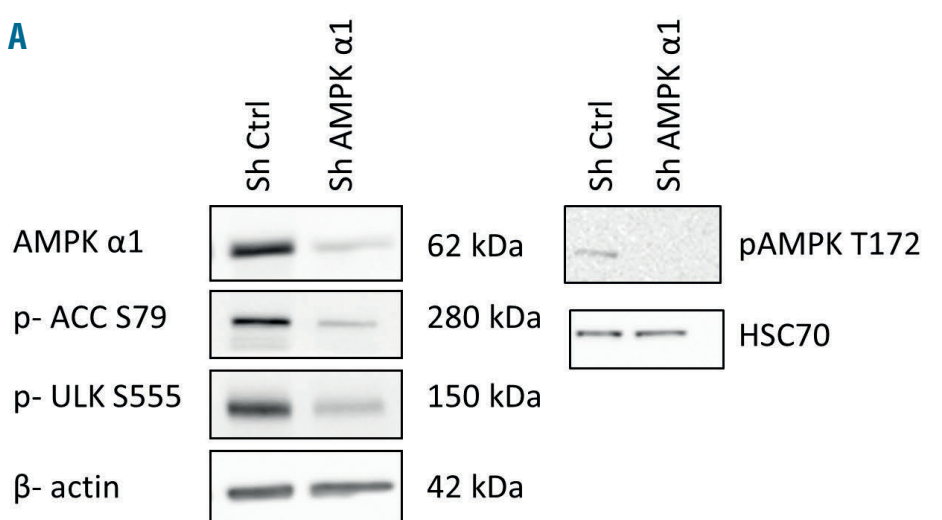

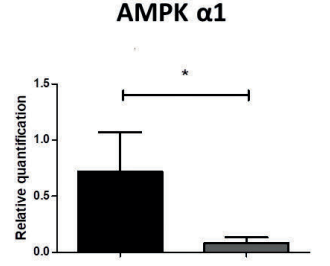

ShCtrl ShAMPK $\alpha 1$

p- ACC

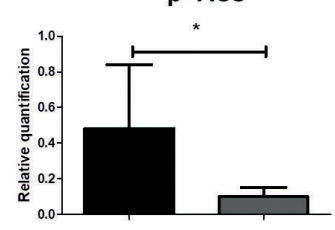

ShCtrl ShAMPK $\alpha 1$

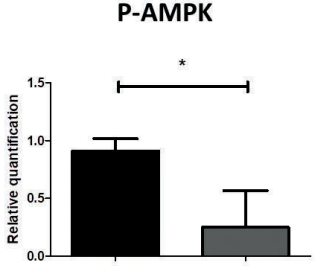

ShCtrl ShAMPK $\alpha 1$

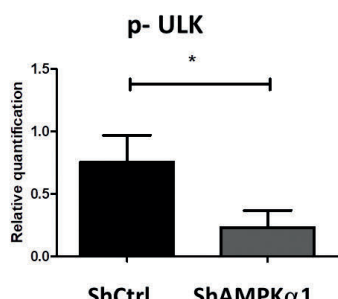

B

C

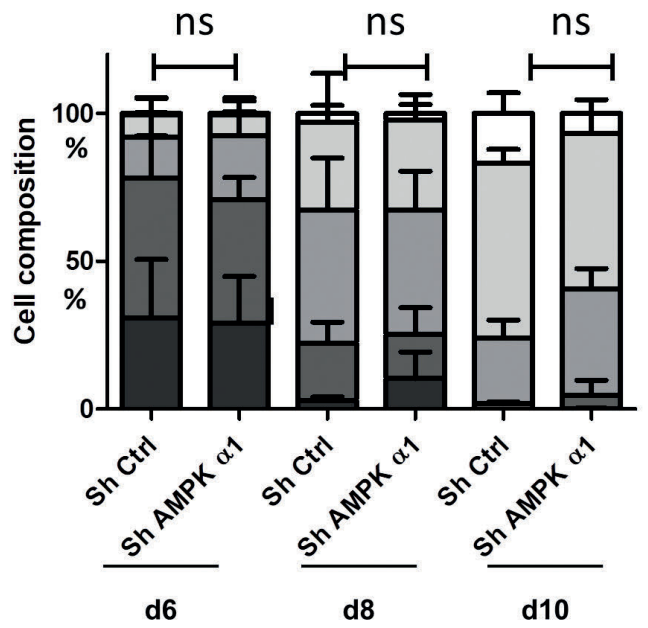

Reticulocytes

Orthochromatic E.

Polychromatic E.

Basophillic E.

Pro E.

Progenitors

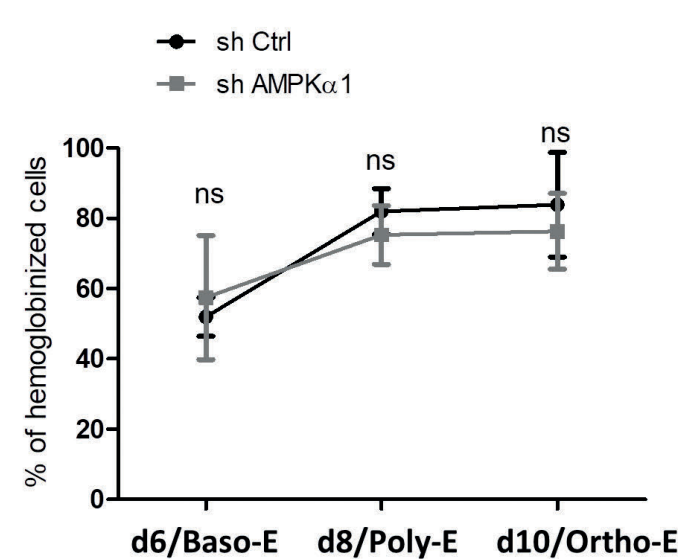

D

E

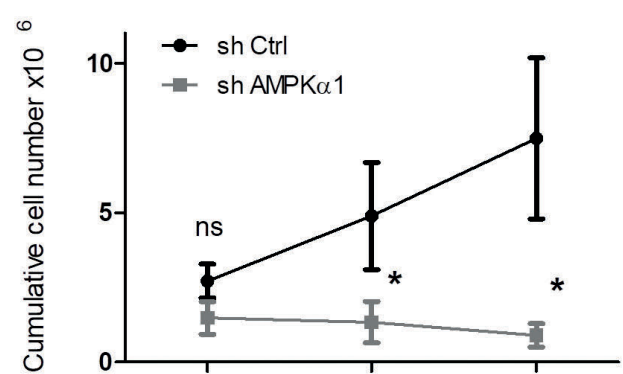

d6/Baso-E d8/Poly-E d10/Ortho-E

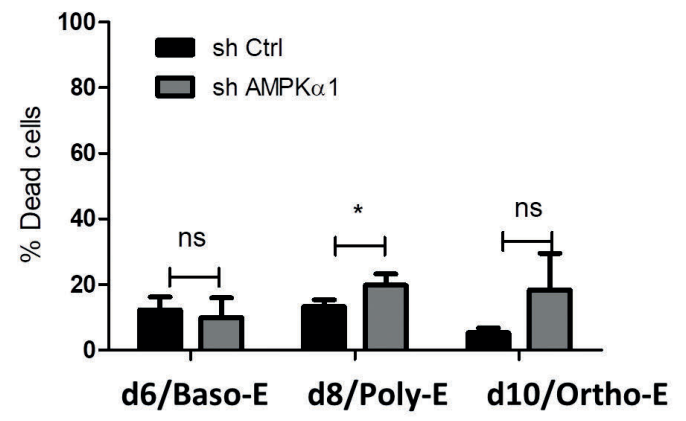

Figure 2. AMPK $\alpha 1$ knockdown reduces erythroblast proliferation without affecting erythroblast maturation. (A) Efficiency of AMPK $\alpha 1$ knockdown: Erythroblasts were infected twice, on days 1 and 4 after CD36 cell sorting, with either a lentivirus coding a scrambled shRNA (sh Ctrl) or an AMPK $\alpha 1$ shRNA (shAMPK $\alpha 1$ ). The efficiency of AMPK $\alpha 1$ knockdown in human primary erythroblasts was determined by anti- $\alpha 1$ AMPK, anti-PT172 AMPK, anti-PS79 ACC and anti-PS555 ULK1 western blots on day 8 or day 10 with the same results. A representative experiment on day 8 is presented. Western blot quantification was performed with anti- $\beta-$ actin or anti-HSC70 antibodies; values are the mean of three independent experiments \pm SD; ns: non-significant, *P<0.05. (B) Effect of shAMPK $\alpha 1$ on erythroid cell maturation. Cell composition for each culture at days 6, 8 and 10. The mean composition \pm SD was calculated based on erythroblast morphology determined by MayGrünwald-Giemsa staining in three independent experiments. (C) Absence of AMPKo1 does not modify the percentage of hemoglobinized cells. The percentage of hemoglobinized cells was determined by benzidine staining at the indicated days of culture and corresponding stage of differentiation determined as in Figure $2 \mathrm{~A}$. (D) Proliferation of shCtrl versus shAMPK 1 erythroblasts. Cumulative cell number was determined by counting cells with the trypan blue exclusion method at day 6 (basophilic erythroblasts), day 8 (polychromatic erythroblasts) and day 10 (orthochromatic erythroblasts) of culture. Results are expressed as the mean \pm SD of three independent experiments; ns: non-significant, ${ }^{*} P<0.05$. (E) Cell death in shAMPK $\alpha 1$ versus shCtrl cells. The proportion of dead cells was determined by trypan blue exclusion dye at days 6,8 and 10 of culture. Results are expressed as the mean \pm SD of three independent experiments; ns: non-significant, *P<0.05. d: day; GPA: glycophorin A; AMPK: AMP-activated protein kinase; ACC: acetyl-CoA-carboxylase; ULK1: Unc-51 like autophagy activating kinase 1; HSC70: heat shock 70kDa protein; Pro-E: pro-erythroblasts; Baso-E: basophilic erythroblasts; Poly-E: polychromatic erythroblasts; Ortho-E: orthochromatic erythroblasts. 
A

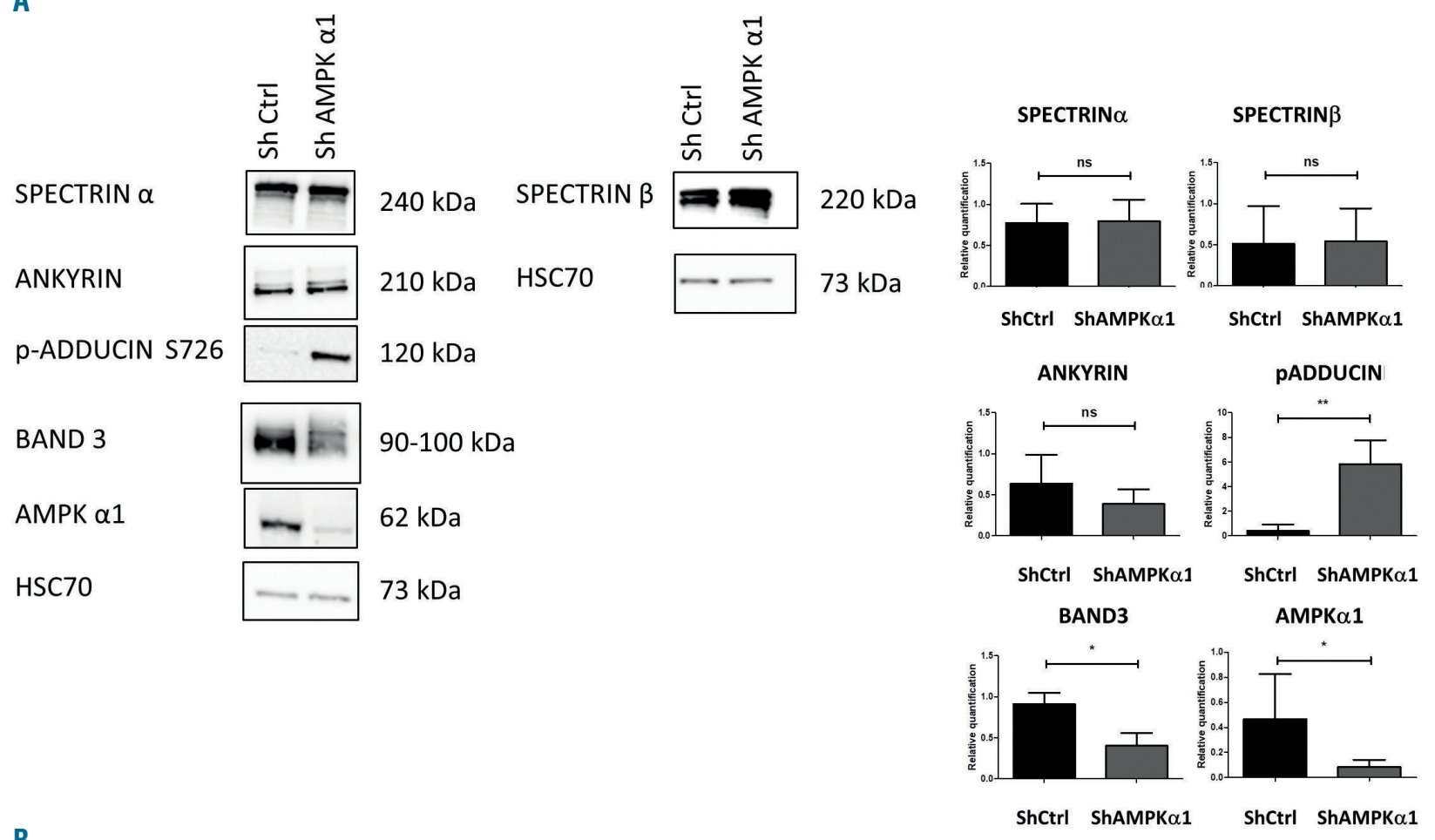

B

d6
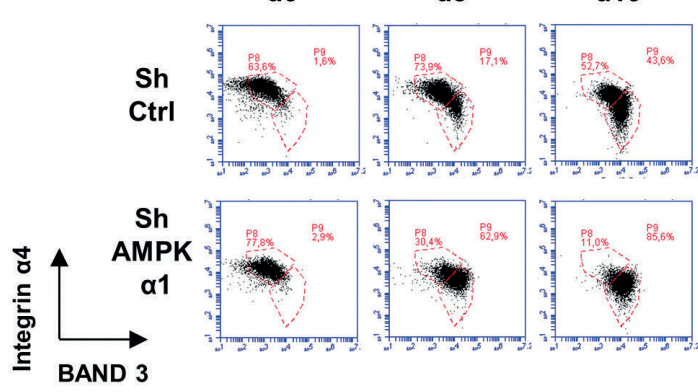

C

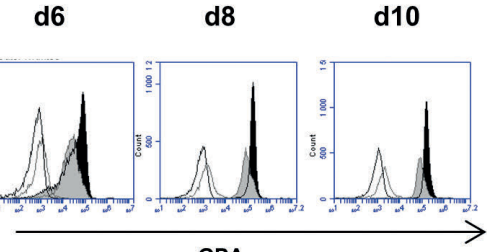

GPA

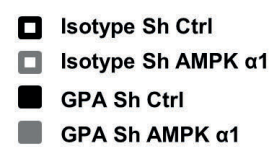

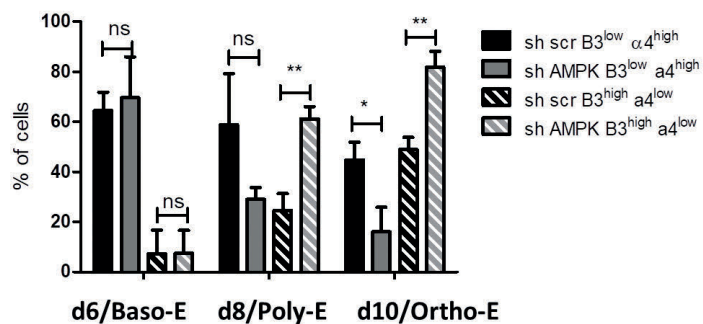

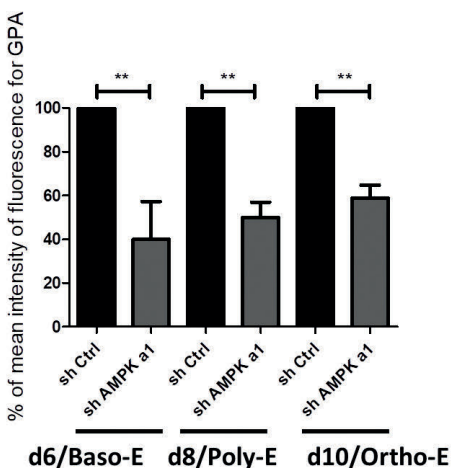

Figure 3. AMPK $\alpha 1$ knockdown disturbs glycophorin A, band 3 expression and phosphorylation of aduccin. (A) Analysis of expression of membrane proteins. Protein extracts from human primary erythroblasts were analyzed by western blot using anti-AMPK $\alpha 1$ antibodies to confirm the knockdown and anti-spectrin $\alpha$ and $\beta$, ankyrin, band 3, p-aduccin S726 antibodies. Anti-HSC70 was used as a loading control. AMPK $\alpha 1$, anti-spectrin $\alpha$, ankyrin, band 3, p-adducin S726 were analyzed on the same western blot, spectrin $\beta$ on a distinct one (representative western blot at day 8 /polychromatic erythroblasts, left panel), the same result was obtained at day 10/polychromatic erythroblasts. The blots were quantified using anti-HSC70 antibodies; values are the mean \pm SD of three independent experiments at day 8 and day 10; ns: non-significant, ${ }^{*} P<0.05$; (right panel). (B) Representative cytometry profile for band $3 / \alpha 4$ integrin gated on GPA-positive cells (left panel) The percentages of band $3^{\text {low }} \alpha 4$ integrin high and band $3^{\text {med }} \alpha 4$ integrin ${ }^{\text {med }}$ in the shCtrl and shAMPK $\alpha 1$ cell populations are plotted in histograms (right panel). Results are expressed as the mean \pm SD of three independent experiments; ns: non-significant, $* P<0.05$; $* * P<0.01$. (C) Expression of GPA determined by FACS. Representative cytometry profiles are shown for GPA at day 6/basophilic erythroblasts, at day 8/polychromatic erythroblasts and at day 10/orthochromatic erythroblasts. Control isotype: unfilled black for shCtrl, unfilled gray for shAMPK 1 1; GPA-labeled: filled black for shCtrl, filled gray for shAMPK $\alpha 1$ ) (left panel). The histogram shows the mean percentage of the GPA fluorescence intensity on the cell surface; $100 \%$ represents the fluorescence intensity for shCtrl cells (right panel). Results are expressed as the mean \pm SD of three independent experiments; ns: non-significant, ${ }^{\star} P<0.05$; $* * P<0.01$. AMPK: AMP-activated protein kinase; HSC70: heat shock 70kDa protein; d: day; B3: band 3; Baso-E: basophilic erythroblasts; Poly-E: polychromatic erythroblasts; Ortho-E: orthochromatic erythroblasts; GPA: glycophorin A. 
A

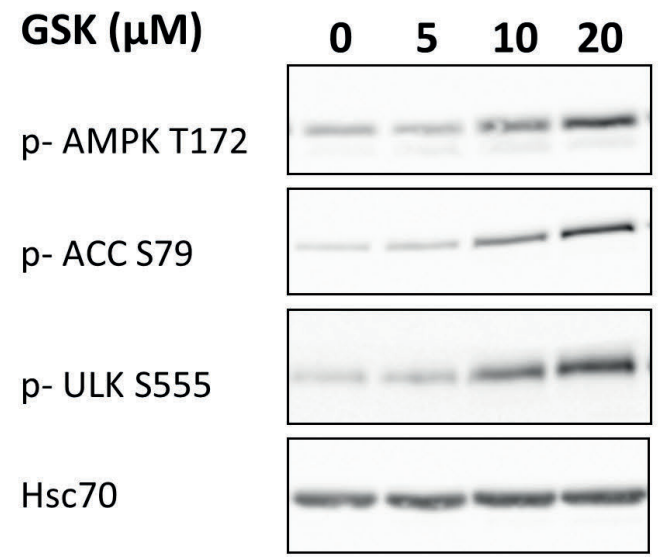

C

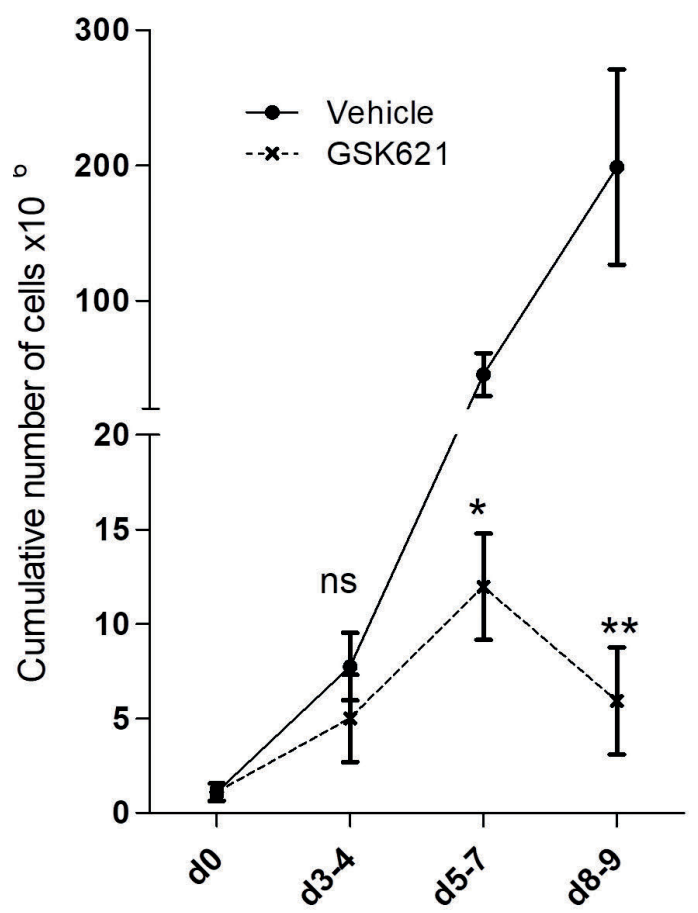

Figure 4. GSK621-mediated AMPK activation decreases the proliferation of mature erythroblasts. (A) GSK621 dose-dependent activation of AMPK in erythroblasts. Western blot analysis of PT172 AMPK 1 1, PS79 ACC and PS555 ULK1 in primary erythroblasts incubated for $3 \mathrm{~h}$ with increasing doses of GSK621. AntiHSC70 was used as a loading control. (B) GSK621 induces massive cell death from days 5-7. The percentage of dead cells was determined by trypan blue exclusion dye. In the three experiments, the days of culture were grouped at the same stage of differentiation for the vehicle-treated cells (see Methods section). (C) Inhibition of erythroblast proliferation by GSK621. Erythroid cells were incubated in the absence (vehicle) or presence of $20 \mu \mathrm{M}$ GSK621 from day 0. Cumulative cell number was determined by counting cells with the trypan blue exclusion method at day 0, days 3-4, days 5-7 and days 8-9 in three independent cultures. (D) GSK621 induces an accumulation of cells in the $S$ phase. Erythroid cells were incubated in the absence (vehicle) or presence of $20 \mu \mathrm{M}$ GSK621 from day 0 to the indicated days. The propidium lodide incorporation assay was performed. A representative experiment is shown; four independent experiments were performed and the results from day 9 are expressed as the mean \pm SD; ns: non-significant, ${ }^{*} P<0.05$. AMPK: AMP-activated protein kinase; ACC: acetyl-CoAcarboxylase; ULK1: Unc-51 like autophagy activating kinase 1; HSC70: heat shock 70kDa protein; d: day.
B
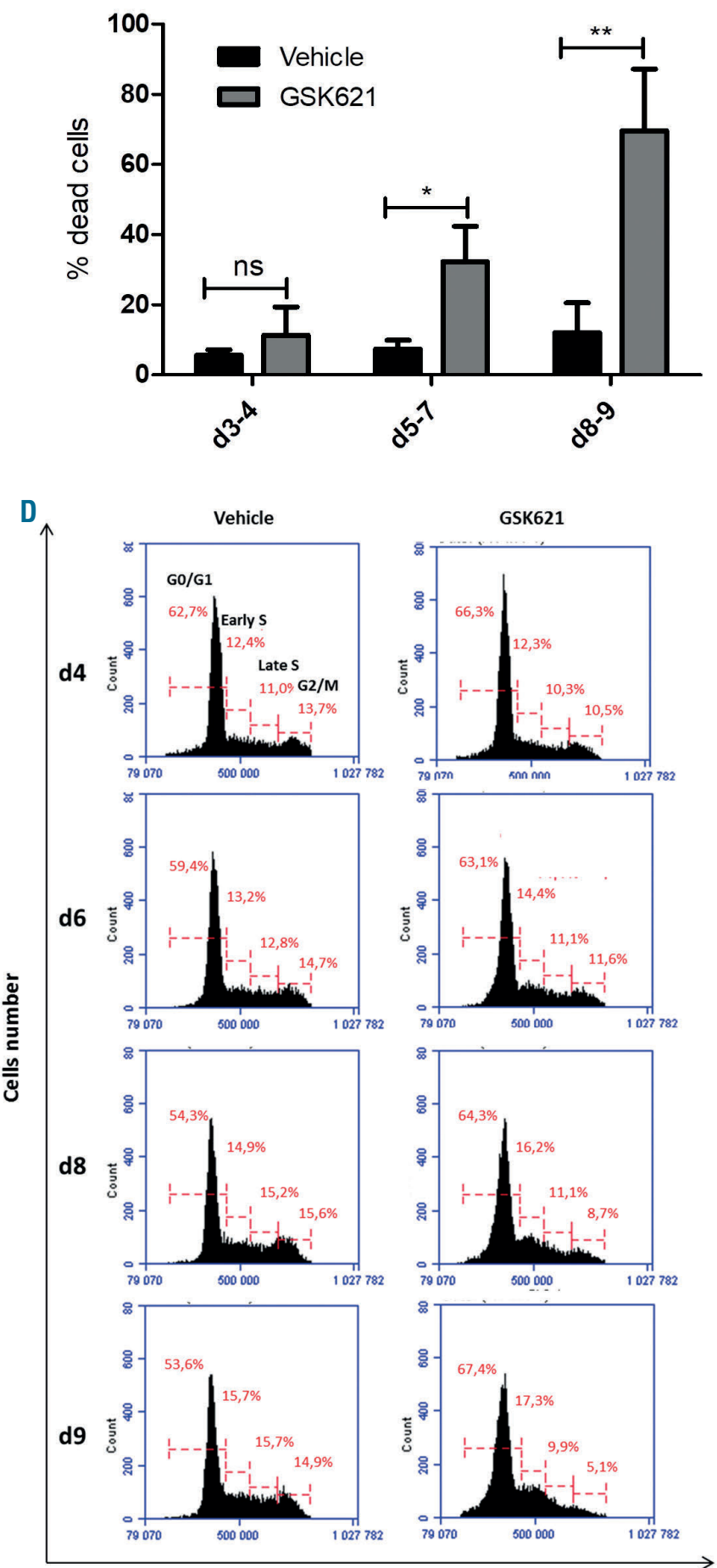

DNA Content

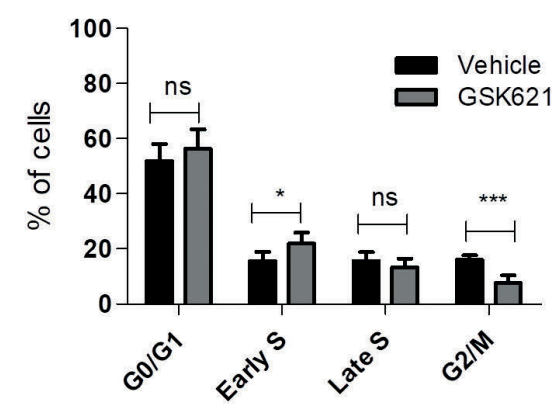


Figure S5). GSK621 provoked 32\% cell death at days 5-7 and $70 \%$ at days 8-9 (Figure 4B). GSK621 dramatically reduced the proliferation of cells with a more drastic impact on the most mature erythroblasts (Figure 4C).

To gain further insight into the inhibition of mature erythroblast proliferation by GSK621, the cell cycle was analyzed by quantification of DNA content with propidium iodide. At days 8 and 9, GSK921 induced a reduction in the number of cells in the G2/M phase of the cell cycle and an increase in cells in the early $S$ phase, demonstrating blockage in the $S$ phase (Figure 4D). The protein level of AMPK substrates involved in the cell cycle, $\mathrm{P}^{2} 3^{16}$ and a target gene of P53, P21 was determined. GSK621-mediated cell cycle arrest was not due to the phosphorylation and consequent stabilization of P53 since there was no variation in their expression, which is in agreement with the absence of defects in G1/S transition (Online Supplementary Figure S6).

We then studied in more detail whether GSK621-mediated AMPK activation could affect erythroblast differentiation. In this set of experiments, at days 3-4 cells were immature and did not synthesize hemoglobin, while at days 8-9, more than $80 \%$ of the cells were hemoglobinized (Figure 5A). In the presence of GSK621, at days 8-9, the percentage of cells that synthesized hemoglobin was very low.

To decipher more precisely the stage at which the GSK621-mediated activation of AMPK induced cell death, erythroblasts were analyzed for GPA and annexin V by flow cytometry (Figure 5B). GSK621 did not affect immature GPA ${ }^{\text {low }}$ cells at days 3-4, but induced massive death of GPA $^{\text {high }}$ erythroblasts at days 5-7 (46\% annexin V-positive cells with GSK621 versus 16\% in control cells) and at days 8-9 (75\% versus $16 \%$, respectively). Indeed, after AMPK activation at days $5-7$, only $3.5 \%$ of erythroblasts were GPA $^{\text {high }}$, in contrast to $46.4 \%$ in control cells. Furthermore, at day 7 only $7.5 \%$ of GSK621-treated cells were band $3^{\text {high }}$ compared to $42 \%$ of control cells. At day 9 , in the control conditions, erythroid cells continued to differentiate, which is in contrast to immature GSK621-treated cells. Furthermore, morphological studies after staining with May-Grünwald-Giemsa confirmed the blockage in maturation. Indeed, in vehicle-treated cultures, at day 9, the population was mainly constituted of polychromatic erythroblasts, and at day 14, orthochromatic erythroblasts and reticulocytes, whereas in the GSK621-treated culture, at days 9 and 14, cells were very immature with large nuclei and uncondensed chromatin; no mature cells were detected at day 14 (Figure 5C). The same results (decreased proliferation and survival, differentiation blockage) were obtained with another direct activator, compound 991 (Online Supplementary Figure S7). Overall, our results show that activation of AMPK by direct activators induced a blockage in the cell cycle, proliferation arrest and death of mature erythroblasts after the basophilic stage.

To reinforce our data, we took advantage of the fact that erythroid progenitors and early precursors can proliferate with delayed differentiation in response to erythropoietin, stem cell factor and dexamethasone. ${ }^{17}$ We maintained the cells for the indicated number of days in culture medium with vehicle, GSK621, dexamethasone + vehicle or dexamethasone + GSK621 (Figure 6A). As expected, the presence of dexamethasone delayed erythroid differentiation, as demonstrated by the absence of a GPA ${ }^{\text {high }}$ population after 7 days and even 9 days of culture. After 7 days, GSK621 induced cell death, as previously described (Figures $4 \mathrm{~B}$ and $5 B$ ), with $54.6 \%$ of cells being positive for annexin $V$ and
$35.3 \%$ being stained by trypan blue; however, immature erythroblasts treated with dexamethasone + GSK621 were resistant to GSK621-induced cell death. Indeed, only $23.4 \%$ of cells were annexin $\mathrm{V}$-positive and $16.6 \%$ were stained by trypan blue (Figure 6A,B).

To confirm that the activation of AMPK in mature erythroblasts provoked cell death, GSK621 was added for 24 and $48 \mathrm{~h}$ on day 9 when the erythroblastic population already contained $35 \%$ of mature GPA ${ }^{\text {high }}$ cells (Figure 6C). The GPA/annexin $\mathrm{V}$ staining clearly demonstrated that GSK621 induced massive death in mature GPA ${ }^{\text {high }}$ cells within less than $48 \mathrm{~h}$. With GSK621, 52\% of the total cells were positive for annexin $V$ and $43 \%$ were stained by trypan blue versus $16 \%$ and $10 \%$, respectively, of the control cells.

Overall, our results demonstrated that the activation of AMPK was deleterious for mature GPA ${ }^{\text {high }}$ cells, specifically in contrast to immature erythroblasts (from the progenitor stage to the basophilic stage), which were not affected.

\section{AMPK activation induced autophagy and apoptotic death of mature erythroblasts}

In erythroblasts, AMPK activation leads to ULK1 phosphorylation at S555 (Figure 4A), which is well known to be important for the induction of autophagy in several types of cells. ${ }^{12}$ In GSK621-treated erythroblasts, LC3B-II accumulation was clearly detected by immunoblotting (Figure 7A, left panel). The induction of autophagy was confirmed by the use of chloroquine, which blocks the degradation of autophagosomes. ${ }^{19}$ Indeed, in addition to GSK621, chloroquine treatment further increased LC3B-II, showing that the activation of AMPK by GSK621 in mature erythroblasts induced autophagy (Figure 7A, right panel).

We, therefore, wondered whether GSK621 provoked caspase-dependent apoptotic cell death and treated cells with a pan-caspase inhibitor Q-VD-OPh (OVD) in addition to GSK621. When caspase activity was blocked by OVD for $48 \mathrm{~h}$ (as demonstrated by the anti-cleaved-caspase 3 immunoblot), mature erythroblasts were protected from GSK621-induced cell death, showing that AMPK activation induced caspase-dependent apoptotic cell death (Figure 7B).

\section{Discussion}

Ampk $\alpha 1^{-}$, Ampk $\beta 1^{\%}$ and Ampk $\gamma 1 \%$ mice develop hemolytic anemia, and the plasma membrane of their red blood cells shows elasticity defects. ${ }^{5-8}$ The membrane composition evolves continuously throughout erythropoiesis and during red blood cell maturation; the defects due to the absence of Ampk are most likely initiated during erythropoiesis. We, therefore, studied the role of AMPK during human erythropoiesis.

As in murine red blood cells, ${ }^{5} \alpha 1$ is the only catalytic subunit expressed in erythroblasts, $\alpha 2$ is not detected and we showed that the heterotrimer $\alpha 1 / \beta 1 / \gamma 1$ is predominant from erythroid progenitors to orthochromatic erythroblasts.

During the earliest stages of terminal differentiation, from progenitors to the basophilic stage, AMPK is activated and then its activation is drastically reduced to the reticulocyte stage. Several kinases and phosphatases regulate AMPK activation. ${ }^{120}$ AMPK is activated by phosphorylation at T172 by three upstream kinases: LKB1, which seems to be constitutively active, CaMKK2 which is activated by an 
A
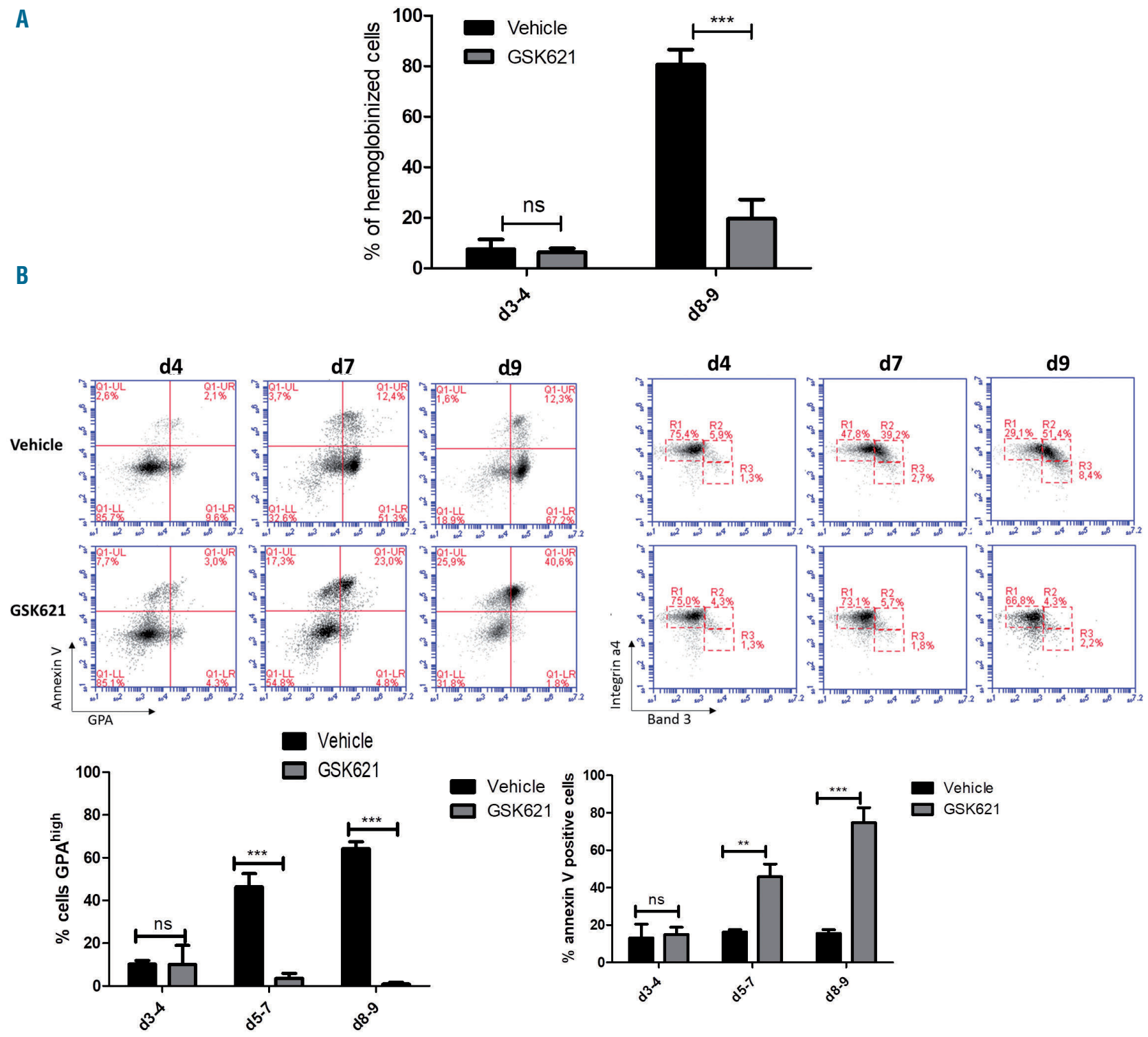

C
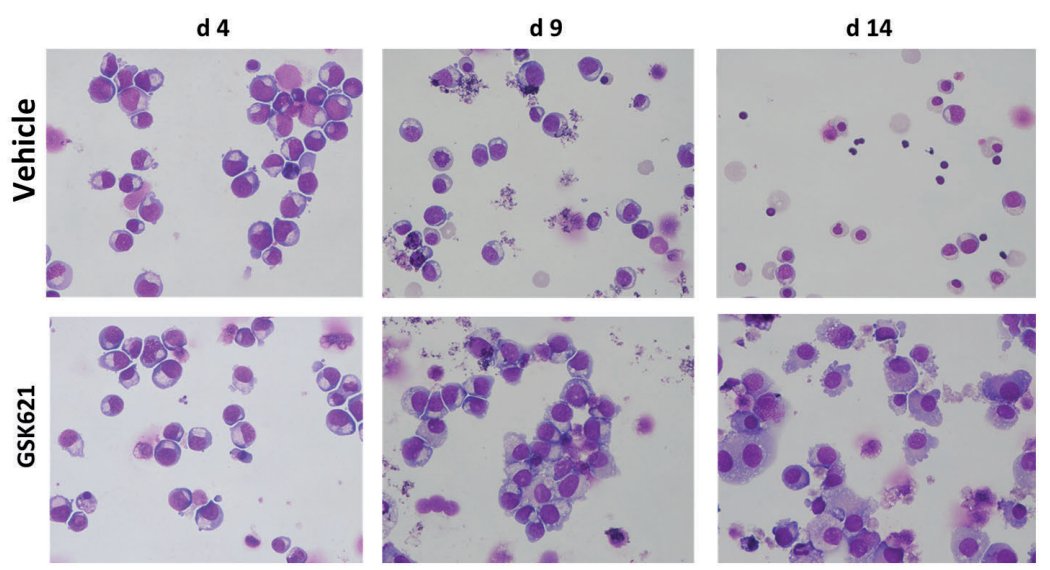

Figure 5. GSK621-mediated AMPK activation specifically and drastically decreases the survival of mature GPA ${ }^{\text {high }}$ erythroblasts. (A) GSK621-dependent AMPK activation reduces the percentage of hemoglobinized cells. The percentage of hemoglobinized cells was determined by benzidine staining after incubation in the absence (vehicle) or presence of $20 \mu \mathrm{M}$ GSK621 from day 0 to the indicated days. (B) GSK621-mediated AMPK activation blocked erythroblast differentiation. Erythroblasts were incubated in the absence (vehicle) or presence of $20 \mu \mathrm{M}$ GSK621 from day 0 to the indicated days. Representative cytometry profiles for GPA/annexin V and band 3/ $\alpha 4$ integrin are shown. For the GPA/annexin V profiles, annexin V-positive cells are shown in the upper part of the quadrant and GPA high cells in the right part. The percentage of GPA high cells and percentage of annexin V-positive cells are represented. Results are expressed as the mean \pm SD of three independent experiments; ns: non-significant, $* P<0.05$. (C) Morphology was analyzed by May-Grünwald-Giemsa staining. Representative experiments at day 4 , day 9 and day 14 are shown. d: day; GPA: glycophorin A. 
A

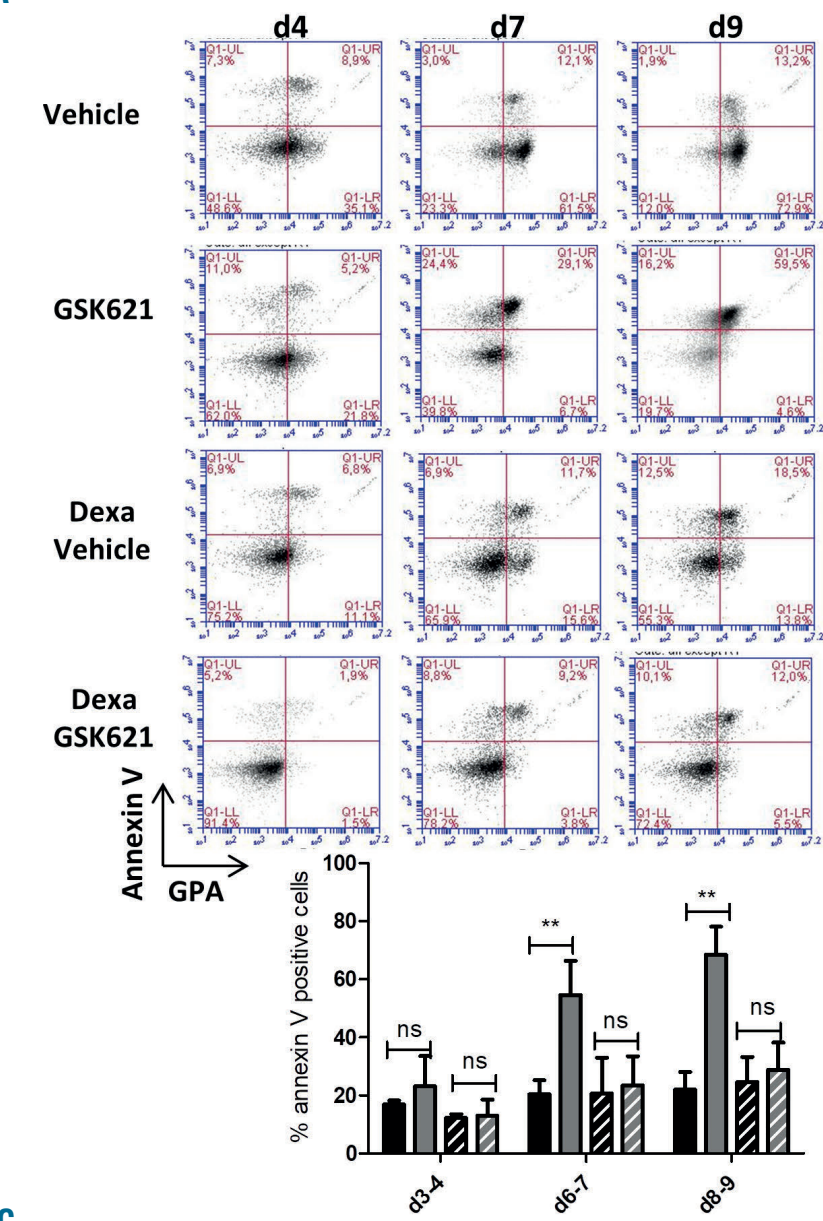

C

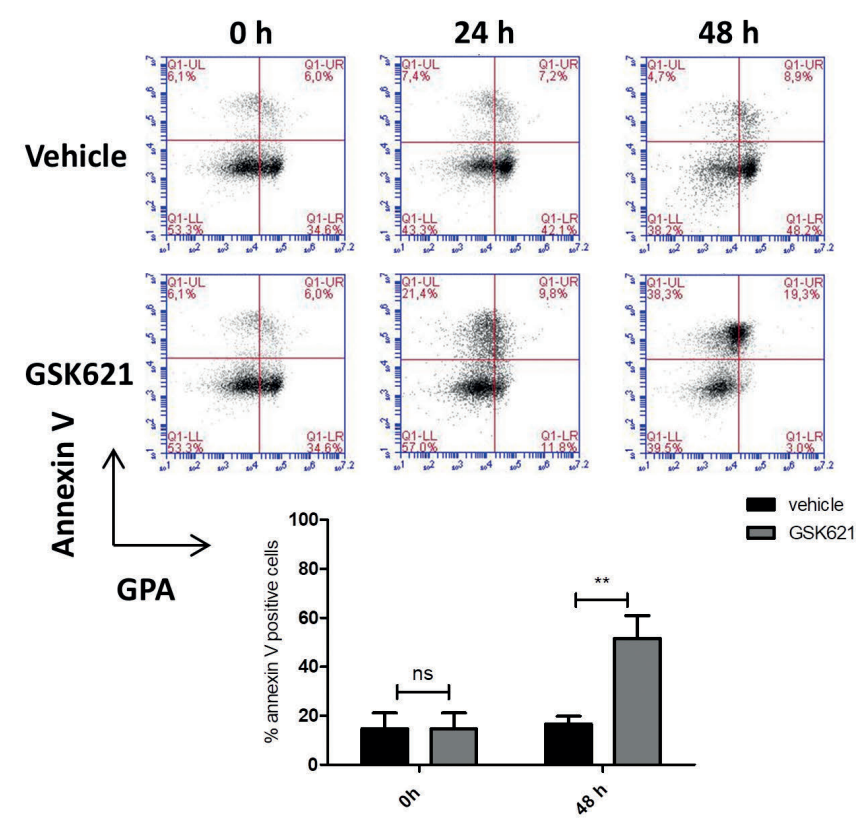

B

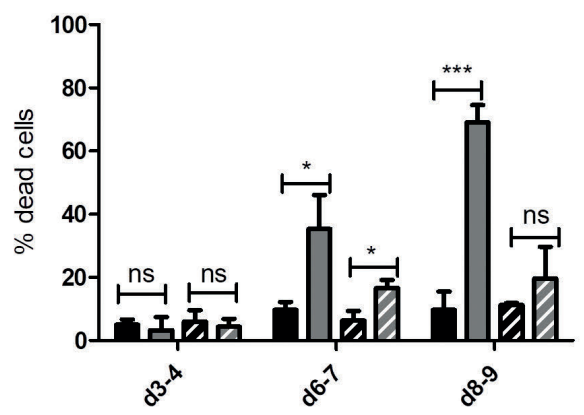

D

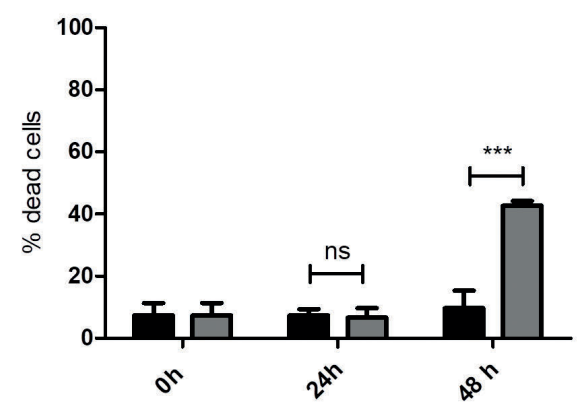

Figure 6. AMPK activation by GSK621 provokes the death of mature GPA ${ }^{\text {nigh }}$ erythroblasts. (A) GSK621 does not increase the percentage of annexin V-positive cells in an immature cell population. Erythroid cells were incubated in the absence (vehicle) or presence of 20 uM GSK621 and 2x10.7 M dexamethasone (Dexa)/vehicle or Dexa/GSK621 from day 0 to the indicated days. Cells were labeled with anti-GPA antibodies and annexin V before analysis by flow cytometry. A representative experiment and the percentage of annexin V-positive cells from three experiments are shown. (B) GSK621 does not induce cell death when the population of erythroblasts is immature. The proportion of dead cells was determined by trypan blue exclusion dye assay. (C) GSK621-mediated AMPK activation specifically induces the death of mature day 9 erythroblasts. Mature erythroblasts were incubated in the absence (vehicle) or presence of $20 \mu \mathrm{M}$ GSK621 for 24 or $48 \mathrm{~h}$. Cells were incubated with anti-GPA antibodies and annexin $\mathrm{V}$ before analysis by flow cytometry. A representative experiment and the percentage of annexin V-positive cells from three experiments are shown (lower panel). (D) The proportion of dead cells was determined by a trypan blue exclusion dye assay. Results are expressed as the mean \pm SD. $* P<0.05, * * P<0.01, * * * P<0.001$. d: day; Dexa: dexamethasone; GPA: glycophorin A; h: hours. 
increase in cytosolic $\mathrm{Ca}^{2+}$, and possibly TAK1, which is activated by cytokines. The phosphatases PP1, PP2A and PP2C dephosphorylate T172 and the kinases GSK3, PKA, PKB, and PKC inhibit AMPK activation; they may contribute to the reduced AMPK activation in mature erythroblasts. Our data from the quantitative mass spectrometry analysis of human erythropoiesis ${ }^{11}$ did not allow us to quantify these kinases and phosphatases because of their absence, their very weak expression or the scarcity of peptides generated. Nevertheless, our western blot studies showed the expression of LKB1 along erythroid differentiation and suggested that LKB1 could be the upstream activating kinase for AMPK $\alpha 1$. Further studies are needed to understand the kinetics of AMPK activation and its upstream regulators during erythroid terminal differentiation.
Our results in human erythroblasts show that knockdown of the expression of the $\alpha 1$ subunit by shRNA induces a decrease in cell proliferation and does not inhibit cell survival or erythroid maturation. Red blood cells from Ampk $\alpha 1^{1 /}$ mice have defects in membrane elasticity leading to hemolytic anemia. The absence of the $\alpha 1$ subunit in human erythroblasts induces important changes in the expression of membrane proteins and could potentially affect the expression of membrane proteins involved later in erythrocyte membrane elasticity. As we previously showed, phosphorylation of adducin at Ser724 is increased in red blood cells from Ampk $\alpha 1^{-1}$ and Ampk $\gamma 1^{1 /}$ mice. Our data demonstrate that this modification is also present earlier in human erythroblasts. Interestingly, in sickle cell disease, the reduction of red blood cell deformability is associ-

A
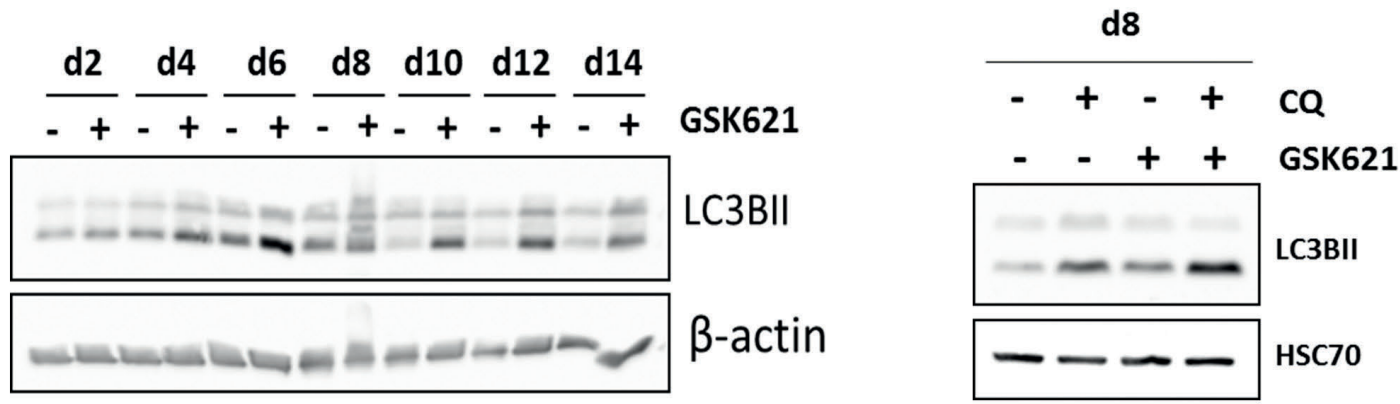

B
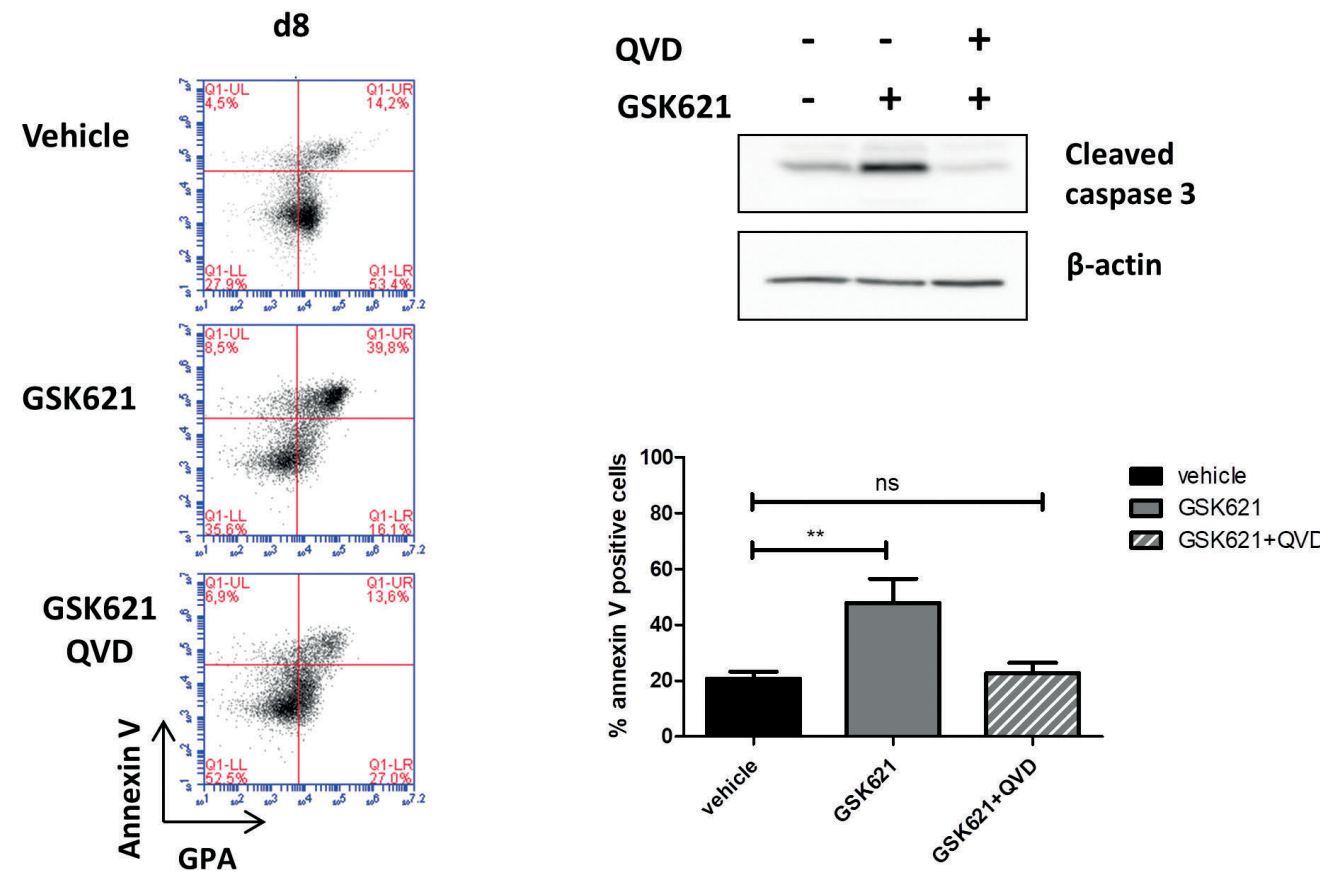

Figure 7. GSK621-mediated AMPK activation leads to autophagy and apoptosis. (A) GSK621-mediated AMPK activation induces autophagy. Erythroid cells were incubated in the absence (vehicle) or presence of $20 \mu \mathrm{M}$ GSK621 from day 0 to the indicated days of culture (left panel). Chloroquine (10 $\mu \mathrm{M}$ ) was added for $4 \mathrm{~h}$ before harvesting the cells (right panel). LC3BII was detected by western blot experiments using specific antibodies. Anti- $\beta$ actin or anti-HSC70 antibodies were used as loading controls. (B) GSK621 provokes the caspase-dependent apoptosis of mature day 8 erythroblasts. Mature erythroblasts were incubated in the absence (vehicle) or presence of $20 \mu \mathrm{M}$ GSK621 or $20 \mu \mathrm{M}$ GSK621 and $10 \mu \mathrm{M}$ QVD for $48 \mathrm{~h}$; cells were labeled with anti-GPA and for annexin V binding and analyzed by flow cytometry. A representative experiment and the percentage of annexin V-positive cells from three experiments are shown. Results are expressed as the mean \pm SD. $* P<0.05, * * P<0.01$. Efficiency of OVD to block caspase activity was determined by western blot using an anti-caspase 3 antibody that specifically detects the cleaved isoform of caspase 3. $\beta$-actin was used as a loading control. d: day; CQ: chloroquine; GPA: glycophorin A; QVD: Q-VD-OPh. 
ated with increased phosphorylation of adducin at Ser $726{ }^{21}$ Thus, it would be interesting to determine whether AMPK plays a role in this pathology. Our results suggest that expression of band 3 is regulated by AMPKa1. Through in vitro studies, Thali et al. identified band 3 as a potential direct substrate for AMPK. ${ }^{22}$ An attractive hypothesis would be that AMPK induces band 3 phosphorylation resulting in an increase in its global expression but a less efficient expression at the cell surface of erythroblasts.

To activate AMPK specifically, we used direct activators of AMPK because these molecules bind directly to the $\beta$ subunit and do not affect the AMP/ATP ratio as metformin does. Several recent studies have demonstrated the involvement and specificity of GSK621 in activating AMPK. ${ }^{12-15}$ In hematopoietic cells, GSK621 has been reported to be more potent in primary acute myeloid leukemia cells and cell lines than the direct activator A-769662..$^{12}$

In the present study, we demonstrated, through the use of direct activators (GSK621 and compound 991), that AMPK activation in mature erythroblasts (GPA $\left.{ }^{\text {high }}\right)$ (polychromatic to reticulocytes) induced apoptotic cell death, whereas no such effect was observed in similarly treated immature erythroblasts. Furthermore, the fact that GSK621 induced the apoptosis of mature erythroblasts after only $48 \mathrm{~h}$ of treatment but did not affect erythroblasts that were maintained in an immature state (by dexamethasone) after 9 days of GSK621 excludes a potential toxic effect due to the accumulation of compounds. We propose that maintaining AMPK activation after the basophilic stage, when AMPK is not normally activated, induces cell cycle arrest followed by the induction of autophagy and caspase-dependent apoptosis. Thus, our work suggests that AMPK activation during the final stages of erythropoiesis is deleterious.

The present work highlights the role of AMPK in erythropoiesis and adds further support to the involvement of AMPK in the regulation of hematopoiesis. In hematopoietic stem cells, AMPK deficiency partially phenocopies the mitochondrial defects observed in Lkb1 mice without affecting hematopoietic stem cell maintenance, ${ }^{23} \mathrm{Obba}$ et al. recently demonstrated that the activation of AMPK is crucial for CSF-1-induced autophagy and human monocyte differentiation into macrophages. ${ }^{24}$ Our results demonstrate the importance of the finely tuned regulation of AMPK during adult human erythropoiesis. This observation is of significant value since deciphering the molecular mechanisms regulating proliferation, survival and differentiation of erythroblasts is necessary to better understand how erythroid progenitors and precursors can physiologically give rise to red blood cells. The use of direct AMPK activators is being considered as a therapeutic treatment in several chronic metabolic diseases. Phase I and II trials investigating the use of the activators PXL770 (clinical trial NCT03395470) and compound 0304 (betagenon.se) are in progress in patients with non-alcoholic hepatic steatosis or type 2 diabetes. These activators could induce the apoptosis of mature erythroblasts in the bone marrow so it will be necessary to analyze hematologic parameters to prevent potential anemia.

\section{Acknowledgments}

ML was funded by the Ministère de l'Enseignement Supérieur et de la Recherche and the Labex GRex. This work was supported by the Laboratory of Excellence Labex GRex.

\section{References}

1. Hardie DG. AMPK: positive and negative regulation, and its role in whole-body energy homeostasis. Curr Opin Cell Biol. 2015;331-337.

2. Hardie DG. AMP-activated protein kinase: an energy sensor that regulates all aspects of cell function. Genes Dev. 2011;25(18):1895-1908.

3. Steinberg GR, Kemp BE. AMPK in health and disease. Physiol Rev. 2009;89(3):1025-1078.

4. Williams T, Brenman JE. LKB1 and AMPK in cell polarity and division. Trends Cell Biol. 2008;18(4):193-198.

5. Foretz M, Guihard S, Leclerc J, et al. Maintenance of red blood cell integrity by AMP-activated protein kinase $\alpha 1$ catalytic subunit. FEBS Lett. 2010;584(16):3667-3671.

6. Foretz M, Hébrard S, Guihard S, et al. The AMPK 1 subunit plays an essential role in erythrocyte membrane elasticity, and its genetic inactivation induces splenomegaly and anemia. FASEB J. 2011;25(1):337-347.

7. Wang S, Dale GL, Song P, Viollet B, Zou MH. AMPKalpha1 deletion shortens erythrocyte life span in mice: role of oxidative stress. J Biol Chem. 2010;285(26):1997619985.

8. Cambridge EL, McIntyre Z, Clare S, et al. The AMP-activated protein kinase beta 1 subunit modulates erythrocyte integrity. Exp Hematol. 2017;45:64-68.e5.

9. Vara-Ciruelos D, Dandapani M, Gray A, Egbani EO, Evans AM, Hardie DG. Genotoxic damage activates the AMPK- $\alpha 1$ isoform in the nucleus via Ca2+/CaMKK2 signaling to enhance tumor cell survival. Mol Cancer Res. 2018;16(2):345-357.

10. Fogarty S, Ross FA, Vara Ciruelos D, Gray A, Gowans GJ, Hardie DG. AMPK causes cell cycle arrest in LKB1-deficient cells via activation of CAMKK2. Mol Cancer Res. 2016;14(8):683-695.

11. Gautier EF, Ducamp S, Leduc M, et al. Comprehensive proteomic analysis of human erythropoiesis. Cell Rep. 2016;16(5): 1470-1484

12. Sujobert P, Poulain L, Paubelle E, et al. Coactivation of AMPK and mTORC1 induces cytotoxicity in acute myeloid leukemia. Cell Rep. 2015;11(9):1446-1457.

13. Liu W, Mao L, Ji F, et al. Targeted activation of AMPK by GSK621 ameliorates $\mathrm{H} 2$ O 2 . induced damages in osteoblasts. Oncotarget. 2017;8(6):10543-10552.

14. Jiang H, Liu W, Zhan S-K, et al. GSK621 targets glioma cells via activating AMP-activated protein kinase signalings. PLoS One. 2016;11(8):e0161017.

15. Chen L, Chen Q, Deng G, et al. AMPK activation by GSK621 inhibits human melanoma cells in vitro and in vivo. Biochem Biophys Res Commun. 2016;480(4):515-521.

16. Jones RG, Plas DR, Kubek S, et al. AMP-activated protein kinase induces a p53-dependent metabolic checkpoint. Mol Cell 2005;18(3):283-293.

17. von Lindern M, Zauner W, Mellitzer G, et al The glucocorticoid receptor cooperates with the erythropoietin receptor and c-Kit to enhance and sustain proliferation of erythroid progenitors in vitro. Blood. 1999;94 (2):550-559.

18. Kim J, Kundu M, Viollet B, Guan K-L. AMPK and $\mathrm{mTOR}$ regulate autophagy through direct phosphorylation of Ulk1. Nat Cell Biol. 2011;13(2):132-141.

19. Mizushima N, Yoshimorim T, Levine B. Methods in mammalian autophagy research. Cell. 2010;140(3):313-326.

20. Carling D, Thornton C, Woods A, Sanders MJ. AMP-activated protein kinase: new regulation, new roles? Biochem J. 2012;445(1):11-27.

21. George A, Pushkaran S, Li L, et al. Altered phosphorylation of cytoskeleton proteins in sickle red blood cells: the role of protein kinase C, Rac GTPases, and reactive oxygen species. Blood Cells Mol Dis. 2010;45(1):4145.

22. Thali RF, Tuerk RD, Scholz R, Yoho-Auchli Y, Brunisholz RA, Neumann D. Novel candidate substrates of AMP-activated protein kinase identified in red blood cell lysates. Biochem Biophys Res Commun. 2010;398(2):296-301.

23. Nakada D, Saunders TL, Morrison SJ. Lkb1 regulates cell cycle and energy metabolism in haematopoietic stem cells. Nature. 2010;468(7324):653-658.

24. Obba S, Hizir Z, Boyer L, et al. The PRKAA1/AMPK 1 pathway triggers autophagy during CSF1-induced human monocyte differentiation and is a potential target in CMML. Autophagy. 2015;11(7): 1114-1129. 